\title{
Determining the $\lg G$ concentrations in bovine colostrum and calf sera with a novel enzymatic assay
}

\author{
M. Drikic, C. Windeyer, S. Olsen, Y. Fu, L. Doepel and J. De Buck ${ }^{*}$ (D)
}

\begin{abstract}
Background: Immune protection in newborn calves relies on a combination of the timing, volume and quality of colostrum consumed by the calf after birth. Poor quality colostrum with inadequate immunoglobulin concentration contributes to failed transfer of passive immunity in calves, leading to higher calf morbidity and mortality. Therefore, estimating colostrum quality and ensuring the transfer of passive immunity on farm is of critical importance. Currently, there are no on-farm tools that directly measure immunoglobulin content in colostrum or serum. The aim of this study was to apply a novel molecular assay, split trehalase immunoglobulin G assay (STIGA), to directly estimate immunoglobulin content in dairy and beef colostrum and calf sera, and to examine its potential to be developed as on-farm test. The STIGA is based on a split version of trehalase TreA, an enzyme that converts trehalose into glucose, enabling the use of a common glucometer for signal detection. In a first study, 60 dairy and 64 beef colostrum and 83 dairy and 84 beef calf sera samples were tested with STIGA, and the resulting glucose production was measured and compared with radial immunodiffusion, the standard method for measuring immunoglobulin concentrations.
\end{abstract}

Results: Pearson correlation coefficients between the methods were determined and the sensitivity, specificity, and accuracy of the test were calculated for different colostrum quality and failed transfer of passive immunity cut-off points. The correlations of the STIGA measured by colorimetric enzymatic reaction compared to radial immunodiffusion for dairy and beef colostrum were 0.72 and 0.73 , respectively, whereas the correlations for dairy and beef sera were 0.9 and 0.85 , respectively. Next, STIGA was tested in a blinded study with fresh colostrum and serum samples where the correlation coefficient was 0.93 and 0.94 , respectively. Furthermore, the performance of STIGA followed by glucometer readings resulted in correlations with radial immunodiffusion of 0.7 and 0.85 for dairy and beef colostrum and 0.94 and 0.83 for dairy and beef calf serum.

Conclusions: A split TreA assay was validated for measurement of the immunoglobulin content of colostrum and calf sera using both a lab-based format and in a more user-friendly format compatible with on-farm testing.

Keywords: Cattle, Colostrum, Immunoglobulins, Passive immunity, Radial immunodiffusion, Split trehalase

\section{Background}

Survival and wellbeing of the newborn calf is strongly dependent on the transfer of immunoglobulins G (IgG) from the colostrum consumed immediately after birth [1]. If the consumed colostrum does not contain sufficient IgG (IgG content $>50 \mathrm{mg} / \mathrm{mL}$ for dairy colostrum and $>100 \mathrm{mg} / \mathrm{mL}$ for beef colostrum [1-3]), the calf will

\footnotetext{
* Correspondence: jdebuck@ucalgary.ca

Department Production Animal Health, Faculty of Veterinary Medicine, University of Calgary, Calgary, AB, Canada
}

likely suffer from failed transfer of passive immunity (FTPI) (IgG content $<10 \mathrm{mg} / \mathrm{mL}$ for dairy calves $[2,4]$ and $<24 \mathrm{mg} / \mathrm{mL}$ for beef calves $[5,6])$. The consequence is a higher risk of mortality and morbidity [1]. With almost 30\% [7] of dairy colostrum samples being poor quality and FTPI occurring in $37.1 \%$ of calves [8], farmers must be encouraged to measure CQ before feeding the colostrum to their calves. To achieve this goal, it is important to offer them a testing method that is user-friendly, fast, accurate, and inexpensive. Currently, there are several on-farm methods used to estimate IgG

(c) The Author(s). 2018 Open Access This article is distributed under the terms of the Creative Commons Attribution 4.0 International License (http://creativecommons.org/licenses/by/4.0/), which permits unrestricted use, distribution, and 
content in bovine colostrum and calf serum. Most of them have the disadvantage of estimating IgG concentration indirectly, which can lead to the overestimation of IgG concentration [7, 9]. Radial immunodiffusion (RID) is considered the gold standard $[10,11]$ but cannot be performed in the field and is slow and costly.

A novel split trehalase IgG quantification assay (STIGA) was developed by our group [12] and is compatible with on-farm application. The STIGA is based on the glycolytic enzyme, trehalase (TreA), which converts trehalose into glucose. TreA is split in two non-functional fragments [13], Tre ${ }^{N}(N)$ and TreA ${ }^{C}(C)$, both fused to streptococcal protein G (pG) [14]. Protein G binds specifically to the constant region of $\operatorname{IgG}(\mathrm{Fc})$ and acts as a sensor for $\operatorname{IgG}$ independent of antigen binding specificity. When the two fusion proteins are incubated with samples containing IgG (e.g. colostrum or serum), they both bind to the Fc of IgG, leading to the dimerization and re-activation of TreA. Re-activated TreA produces glucose from trehalose, which can be detected by a colorimetric assay (STIGA, Fig. 1) or by glucometer (STIGA ${ }^{\text {FIELD }}$; Fig. 1).

The aim of this study was to use STIGA to directly estimate IgG concentration in beef and dairy colostrum samples and in calf serum samples, to compare its performance to RID and to examine its potential to be developed as on-farm test.

\section{Methods}

\section{Sample collection}

Dairy colostrum $(n=60)$ and serum samples $(n=83)$ were randomly selected from samples collected for a previous study [7]. Colostrum samples were collected from 13 dairy farms in central Alberta between February and July of 2012. Samples were collected by the farm owners, frozen at $-20{ }^{\circ} \mathrm{C}$ and transported to the University of Calgary where they were stored at $-80{ }^{\circ} \mathrm{C}$. Serum samples were collected during the same period by research personnel from bull and heifer calves $>24 \mathrm{~h}$ and $\leq 8 \mathrm{~d}$ of age. The samples were stored on ice and transported to the University of Calgary where the serum was harvested by centrifugation at $1,800 \times g$ at $4{ }^{\circ} \mathrm{C}$ for $25 \mathrm{~min}$. Serum samples were also stored at $-80^{\circ} \mathrm{C}$. Beef colostrum $(n=64)$ and serum samples $(n=84)$ were collected during calving seasons (January through May) from 2014 to 2016 from six privately-owned cow-calf operations in Alberta. Beef colostrum and blood samples were processed according to the same protocol as the dairy samples. The IgG concentrations in the dairy colostrum and serum samples were determined by RID by Prairie Diagnostic Laboratories (University of Saskatchewan, Saskatoon, SK) while IgG content in the beef colostrum and serum samples was determined by the Quality Assurance Laboratory of the Saskatoon Colostrum Company Ltd. (SCCL, University of Saskatchewan, Saskatoon, SK) by RID. Dairy colostrum $(n=20)$ and calf serum samples $(n=25)$ used in the blinded study were obtained from the Quality Assurance Laboratory of SCCL where they were randomly selected and tested by RID for this purpose.

\section{Strains, plasmids, and other materials}

Purified bovine IgG $(12.8 \mathrm{mg} / \mathrm{mL})$ used for standard curves was purchased from Sigma-Aldrich (Oakville, Canada). Plasmids used in this work were described previously [12]. In short, the gene coding for $E$. coli glycolytic enzyme TreA [13] was split in two fragments, TreA ${ }^{N}$ (198 bp long) and TreA ${ }^{C}$ (1,368 bp long) through PCR amplification. Each gene fragment was fused with the coding sequence of protein G [14] (residues: 270-324; AC: P19909) and cloned

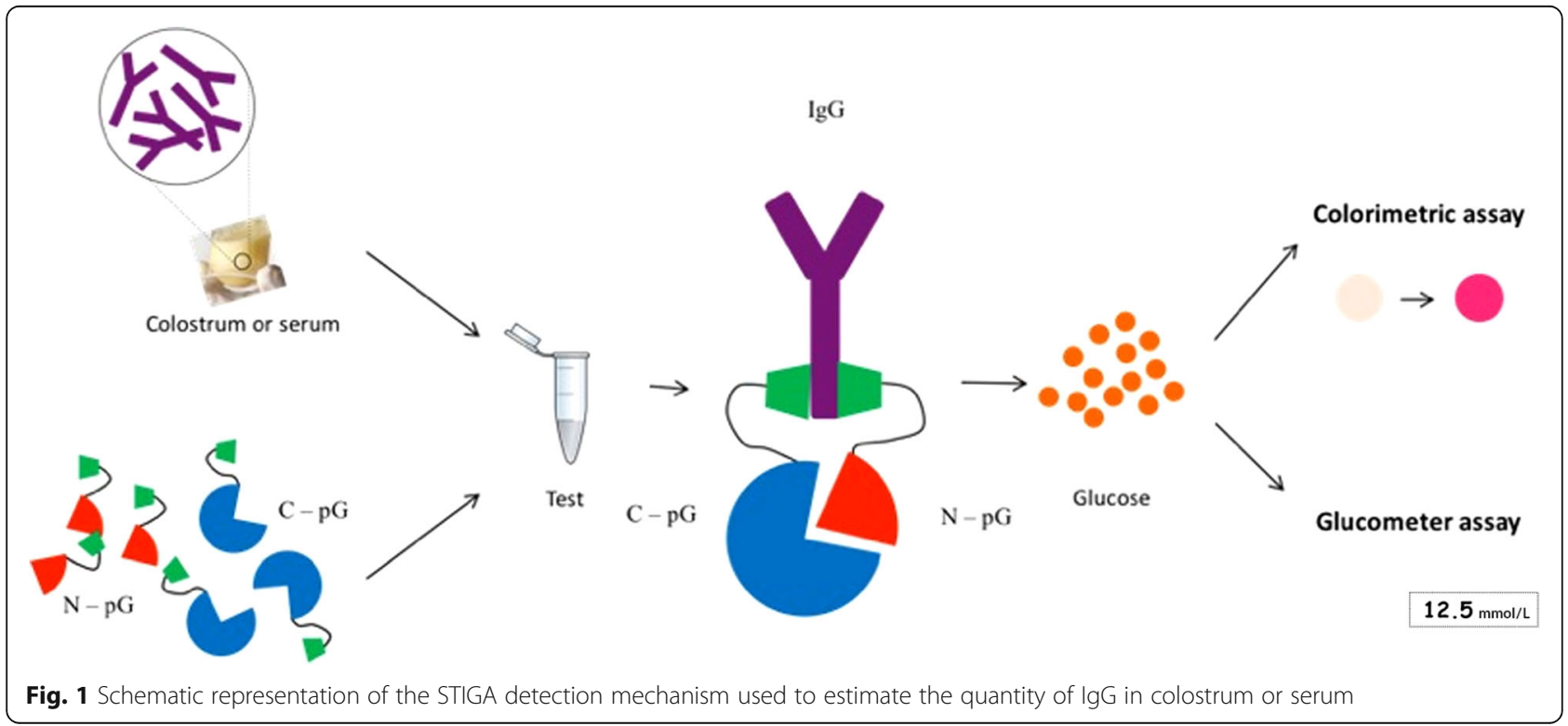


in pETDuet expression vector (Novagen; Oakville, Canada) using NcoI and AvrII restriction sites.

\section{Protein purification and lyophilisation}

Proteins were recombinantly expressed in BL-21 $\Delta$ TreA strain and purified on Ni-NTA resin as previously described [12]. Briefly, BL-21 $\Delta$ TreA cultures were induced with $0.5 \mathrm{mmol} / \mathrm{L}$ of IPTG (isopropil- $\beta$-D-1-tiogalattopiranoside) (UBP Bio; Aurora, Colorado, USA) and harvested after $3 \mathrm{~h}$ at $37^{\circ} \mathrm{C}$. Bacterial pellets with recombinant proteins were resuspended in $6 \mathrm{~mol} / \mathrm{L}$ guanidinium buffer, sonicated and loaded on equilibrated Ni-NTA resin (Thermo-Fisher Scientific; Ottawa, Canada). Proteins were refolded on resin during washing steps containing gradually decreasing guanidinium- $\mathrm{HCl}$ concentrations and eluted in Elution buffer containing $250 \mathrm{mmol} / \mathrm{L}$ of Imidazole. Protein preparations used in the blinded study were purified using AKTA pure system (GE Healthcare Life sciences, Pittsburgh, Pennsylvania, USA). Briefly, 0.5 L of recombinant cultures were induced, lysed as described previously. After lysis, the samples were resuspended in $40 \mathrm{~mL}$ of denaturing resuspension buffer, loaded on HisTrap HP $1 \mathrm{~mL}$ column (GE Healthcare Life sciences, Pittsburgh, Pennsylvania, USA), refolded on column by continuously decreasing concentration of guanidinium- $\mathrm{HCl}$ during the wash step and eluded in native elution buffer $(0.5 \mathrm{~mol} / \mathrm{L}$ imidazole).

Finally, all protein preparations were dialyzed against $1 \mathrm{~L}$ of sodium maleate buffer $(50 \mathrm{mmol} / \mathrm{L}, \mathrm{pH} 6)$ with Snakeskin (Thermo-Fisher Scientific; Ottawa, Canada) for $24 \mathrm{~h}$ at $25{ }^{\circ} \mathrm{C}$ and protein concentration was determined by Qubit assay (Thermo-Fisher Scientific; Ottawa, Canada). Lyophilized reagents were prepared as described previously [12]. Briefly, proteins were mixed in a1 to 1 weight ratio with BSA, frozen in microtiter plate wells at $-80^{\circ} \mathrm{C}$ and then lyophilized over night at $-85^{\circ}$ $\mathrm{C}$ and $200 \mathrm{mT}$.

\section{Split trehalase immunoglobulin G assay (STIGA)}

The STIGA quantification assays were performed in two ways. Glucose measurements were determined with a GOx-HRP colorimetric assay for all samples (STIGA) and a sample subset chosen randomly (dairy colostrum $n=14$; beef colostrum $n=14$; dairy calf sera $n=18$; and beef calf sera $n=18$ ) was analyzed with a glucometer test strip based assay (STIGA ${ }^{\text {FIELD }}$ ).

GOx-HRP colorimetric STIGA: Colostrum and calf serum samples were diluted in sodium maleate buffer (50 mmol/L, pH 6) (dairy colostrum 1 to 2,000; beef colostrum 1 to 4,000; dairy and beef calf serum 1 to 1,000). STIGA was performed with $20 \mu \mathrm{g}$ of C-pG and $5.2 \mu \mathrm{g}$ of $\mathrm{N}$-pG (1 to 1 mole ratio) for colostrum or $10 \mu \mathrm{g}$ of C-pG and $2.6 \mu \mathrm{g}$ of N-pG for serum in sodium maleate buffer with $250 \mathrm{mmol} / \mathrm{L}$ of trehalose (Sigma-Aldrich; Oakville,
Canada) in a final volume of $150 \mu \mathrm{L}$. In the blinded study, STIGA was performed with small modifications: $5 \mu \mathrm{g}$ of of C-pG and $1.3 \mu \mathrm{g}$ of N-pG were used and both colostrum and serum were diluted 1 to 1,000 in sodium maleate buffer. The glucose concentration was measured using glucose oxidase form Aspergillus niger $(2.6 \mathrm{U} / \mathrm{mL}$; Sigma Aldrich; Oakville, Canada), horseradish peroxidase (0.2 U/mL; Sigma-Aldrich; Oakville, Canada), and O-dianisidine ( $0.5 \mathrm{mmol} / \mathrm{L}$; Sigma-Aldrich; Oakville, Canada) in sodium maleate buffer $(50 \mathrm{mmol} / \mathrm{L}, \mathrm{pH}$ 6). Absorbance (optical density; OD) was measured every minute for $90 \mathrm{~min}$ with an EnSpire multimode plate reader at 450 nm (PerkinElmer; Waltham, Massachusetts, USA).

Glucose test strips based STIGA (STIGA ${ }^{\text {FIELD): This }}$ assay was performed with lyophilized protein preparations. Lyophilized proteins were resuspended in $150 \mu \mathrm{L}$ of sodium-maleate buffer with $250 \mathrm{mmol} / \mathrm{L}$ of trehalose containing the same colostrum or serum dilution used in previous assay. Glucose production was measured by Accu-Chek Aviva Blood Glucometer (Roche; Mississauga, Canada) and test strips after $90 \mathrm{~min}$.

\section{Statistical analysis}

GOx-HRP colorimetric STIGA: The IgG content of dairy and beef colostrum and sera analyzed with the STIGA was correlated with RID-determined IgG concentration using Pearson correlation coefficients in Excel (Microsoft). Sensitivity, specificity, positive (PPV) and negative predicted values (NPV) and accuracy were calculated for different OD cut-off points. The threshold for adequate quality colostrum was set at $50 \mathrm{mg} / \mathrm{mL}$ [1-3] for dairy colostrum and at $100 \mathrm{mg} / \mathrm{mL}$ for beef colostrum. Because there is no reported established cut-off for beef colostrum, the value of $100 \mathrm{mg} / \mathrm{mL}$ was used based on the equation: adequate colostrum concentration $(\mathrm{mg} / \mathrm{mL})=[24 \mathrm{mg} / \mathrm{mL}$ (adequate passive immunity) $\times 3.8 \mathrm{~L}$ (plasma volume for average birth weight of $42 \mathrm{~kg}$ ) $] \div[0.3$ (estimated efficiency of absorption) $\times 3 \mathrm{~L}$ (estimated volume of colostrum consumed in $24 \mathrm{~h}$ )]. Sensitivity, specificity, PPV, NPV, and accuracy were calculated using RID as gold standard with the threshold for FTPI for dairy calves at $10 \mathrm{mg} / \mathrm{mL}$ for dairy calves $[2,4]$ and at $24 \mathrm{mg} / \mathrm{mL}$ for beef calves $[5,6]$. Four colostrum and four serum samples were run in triplicates on two different days to calculate intra-assay CV\% and inter-assay $\mathrm{CV} \%$.

Glucose test strips based STIGA (STIGA ${ }^{\text {FIELD): The }}$ colostrum and sera IgG values determined by STIGAFIELD were correlated with RID determined IgG concentrations by Pearson coefficient correlation.

\section{Results}

\section{Detection of IgG in bovine colostrum}

The Pearson correlation coefficient between STIGA and RID for dairy colostrum was 0.72 (Fig. 2a), whereas 
for beef colostrum the correlation coefficient was 0.73 (Fig. 2b). With dairy colostrum samples, STIGA had the highest sensitivity (64.7\%) and specificity (93\%) when an OD of 0.9 was used as the cut-off (Table 1). Test positive (poor quality) dairy samples had a $71.4 \%$ chance of being truly poor quality (i.e., PPV) and test negative (adequate quality) samples had an $84.8 \%$ chance of being truly adequate (i.e., NPV). STIGA identified 23\% of analyzed colostrum samples to be of poor quality whereas RID identified $28.3 \%$ of samples as poor quality.

For beef colostrum, STIGA reached its highest sensitivity (83.3\%) and specificity (90.3\%) when an OD of 0.8 was used as the cut-off value (Table 2.). At this cut-off, the beef colostrum had a PPV of $66.7 \%$ and a NPV of $95.9 \%$. STIGA identified $23.4 \%$ of colostrum samples as poor quality, whereas with RID $18.8 \%$ of samples were poor quality.

In both sample groups the background glucose was undetectable prior to addition of STIGA reagents (data not shown).

\section{Detection of IgG in calf serum}

The Pearson correlation coefficient between serum RID-determined IgG and STIGA-determined IgG was

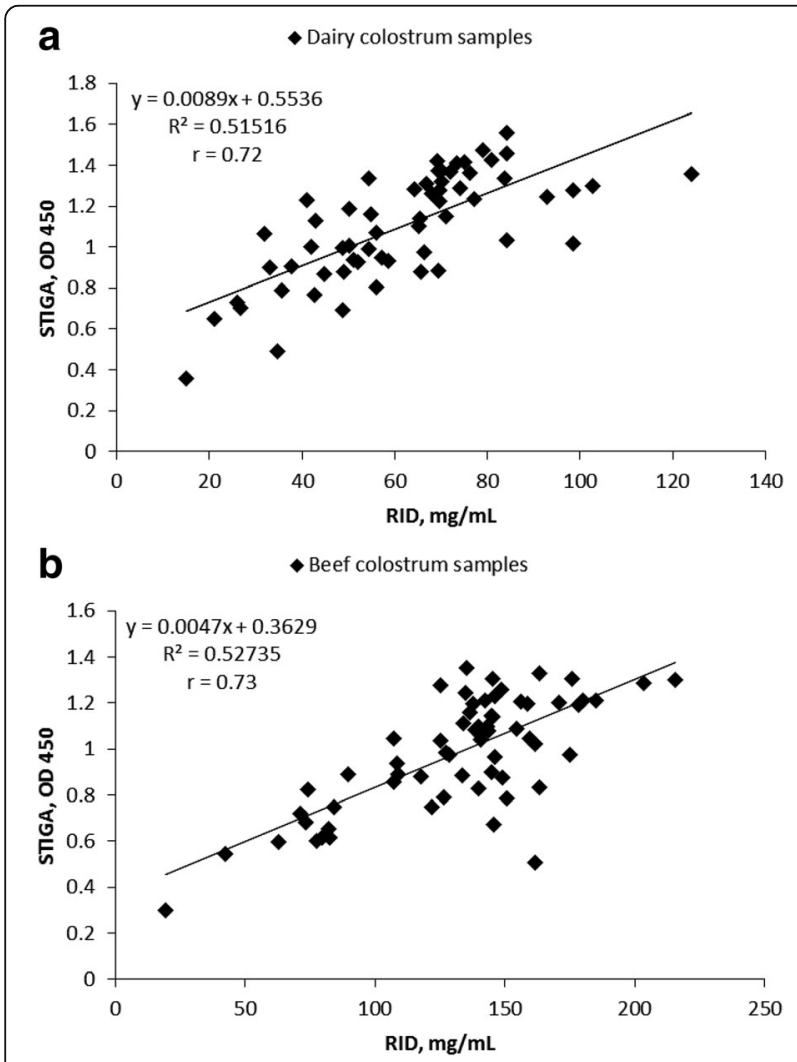

Fig. 2 Correlation between RID determined IgG concentrations in colostrum and glucose levels determined by STIGA. Scatter plot comparing lgG concentration measured by STIGA (OD 450) and by RID $(\mathrm{mg} / \mathrm{mL})$ in: $\mathbf{a}$, dairy colostrum $(n=60)$; $\mathbf{b}$, beef colostrum $(n=64)$
Table 1 Diagnostic test characteristics for STIGA in colostrum

\begin{tabular}{cccccc}
\hline Cut point, OD 450 & Accuracy, $\%$ & $\mathrm{Se}, \%$ & $\mathrm{Sp}, \%$ & $\mathrm{PPV}, \%$ & $\mathrm{NPV}, \%$ \\
\hline $\begin{array}{c}\text { Dairy colostrum } \\
0.6\end{array}$ & 75.0 & 11.8 & 100.0 & 100.0 & 74.1 \\
0.7 & 78.3 & 23.5 & 100.0 & 100.0 & 76.8 \\
0.8 & 85.0 & 47.1 & 100.0 & 100.0 & 82.7 \\
0.9 & 85.0 & 64.7 & 93.0 & 78.6 & 87.0 \\
1.0 & 78.3 & 76.5 & 79.1 & 59.1 & 89.5 \\
1.1 & 75.0 & 88.2 & 69.8 & 53.6 & 93.8 \\
1.2 & 68.3 & 94.1 & 58.1 & 47.1 & 96.2 \\
Beef colostrum & & & & & \\
0.6 & 84.4 & 25.0 & 98.1 & 75.0 & 85.0 \\
0.7 & 90.6 & 66.7 & 96.2 & 80.0 & 92.6 \\
0.8 & 89.1 & 83.3 & 90.4 & 66.7 & 95.9 \\
0.9 & 79.7 & 100.0 & 75.0 & 48.0 & 100.0 \\
1.0 & 71.9 & 100.0 & 65.4 & 40.0 & 100.0 \\
1.1 & 53.1 & 100.0 & 42.3 & 28.6 & 100.0 \\
1.2 & 42.2 & 100.0 & 28.8 & 24.5 & 100.0 \\
\hline Accura & & & & & \\
\hline
\end{tabular}

Accuracy, sensitivity (Se), specificity (Sp), positive predictive value (PPV) and negative predictive value (NPV) calculated for OD cut points for detecting adequate quality colostrum with STIGA with cut-offs of $50 \mathrm{mg} / \mathrm{mL} \mathrm{lgG}$ for dairy colostrum and $100 \mathrm{mg} / \mathrm{mL}$ of beef colostrum determined by RID; for dairy colostrum $(n=60)$ and beef colostrum $(n=64)$

Table 2 Diagnostic test characteristics for STIGA in calf serum

\begin{tabular}{clllll}
\hline Cut point, OD 450 & Accuracy, \% & Se, \% & Sp, \% & PPV, \% & NPV, \% \\
\hline Dairy calf serum & & & & & \\
0.2 & 91.6 & 77.8 & 98.2 & 95.5 & 90.2 \\
0.3 & 86.7 & 100.0 & 80.4 & 71.1 & 100.0 \\
0.4 & 67.5 & 100.0 & 51.8 & 50.0 & 100.0 \\
0.5 & 55.4 & 100.0 & 33.9 & 42.2 & 100.0 \\
0.6 & 45.8 & 100.0 & 19.6 & 37.5 & 100.0 \\
0.7 & 41.0 & 100.0 & 12.5 & 35.5 & 100.0 \\
0.8 & 34.9 & 100.0 & 3.6 & 33.3 & 100.0
\end{tabular}

Beef calf serum

\begin{tabular}{llllll}
0.1 & 85.7 & 7.7 & 100.0 & 100.0 & 85.5 \\
0.2 & 90.5 & 38.5 & 100.0 & 100.0 & 102.9 \\
0.3 & 92.9 & 69.2 & 97.2 & 81.8 & 94.5 \\
0.4 & 83.9 & 100.0 & 91.5 & 46.4 & 116.1 \\
0.5 & 52.4 & 100.0 & 43.7 & 24.5 & 100.0 \\
0.6 & 31.0 & 100.0 & 18.3 & 18.3 & 100.0 \\
0.7 & 16.7 & 100.0 & 1.4 & 15.7 & 100.0 \\
\hline
\end{tabular}

Accuracy, sensitivity (Se), specificity (Sp), positive predictive value (PPV), and negative predictive value (NPV) calculated for OD cut points for detecting FTPI with STIGA with cut-offs of $10 \mathrm{mg} / \mathrm{mL} \mathrm{lgG}$ for dairy calf sera and $24 \mathrm{mg} / \mathrm{mL}$ for beef calf sera determined by RID; for dairy calf sera $(n=83)$ and beef calf sera $(n=84)$ 
0.9 for dairy samples (Fig. 3a) and 0.85 for beef samples (Fig. 3b). The highest sensitivity (77.8\%) and specificity (98.2\%) by STIGA was reached at an OD of 0.2 (Table 2) in dairy calf serum samples. With beef calf sera, the highest sensitivity (69.2\%) and specificity (97.2\%) were reached at an OD of 0.3 (Table 2). In dairy calf serum samples, STIGA had a $95 \%$ chance of correctly identifying FTPI and 90\% chance of correctly showing that the transfer of passive immunity had occurred whereas in beef calf serum samples, STIGA had $75 \%$ and $94.5 \%$ chance of correctly identifying FTPI or successful transfer of passive immunity, respectively. FTPI was observed in $26.5 \%$ of dairy calf serum samples and $13 \%$ of beef calf serum samples by STIGA, compared with $32.5 \%$ and $15.5 \%$, respectively, diagnosed by RID.

In both sample groups the background glucose was undetectable prior to addition of STIGA reagents (data not shown).

\section{Detection of IgG by STIGA in samples of unknown IgG concentration (blinded study)}

STIGA was used to detect total IgG content in fresh dairy colostrum and serum samples (recent samples that were frozen only once) of IgG concentrations unknown to the researchers. The concentration obtained by STIGA was correlated with RID and the obtained correlation coefficients were 0.93 for colostrum samples and 0.94 for serum samples (Fig. 4a and b). High correlation values ( $>0.8$ for colostrum and $>0.9$ for sera) were observed after $10 \mathrm{~min}$ of run time (Fig. $4 \mathrm{c}$ and d). STIGA reached the highest sensitivity (100\%) and specificity (71.4\%) for detecting good quality colostrum at an OD of 0.5 (Table 3), while it reached the highest sensitivity (100\%) and specificity (94.7\%) for detecting FTPI at an OD of 0.4 (Table 3). STIGA was able to correctly identify poor quality colostrum (i.e. PPV) or adequate quality colostrum (i.e. NPV) in $86.8 \%$ or $100 \%$ of cases, respectively. In serum samples STIGA had a PPV of $85.7 \%$ and NPV of $100 \%$, respectively.

Four colostrum and four serum samples with different IgG concentrations were analyzed to calculate inter and intra assay variability. Intra and inter assay variability for colostrum samples were $3.5 \%$ and $11.5 \%$, and for the serum samples, $2.5 \%$ and $8.1 \%$, respectively.
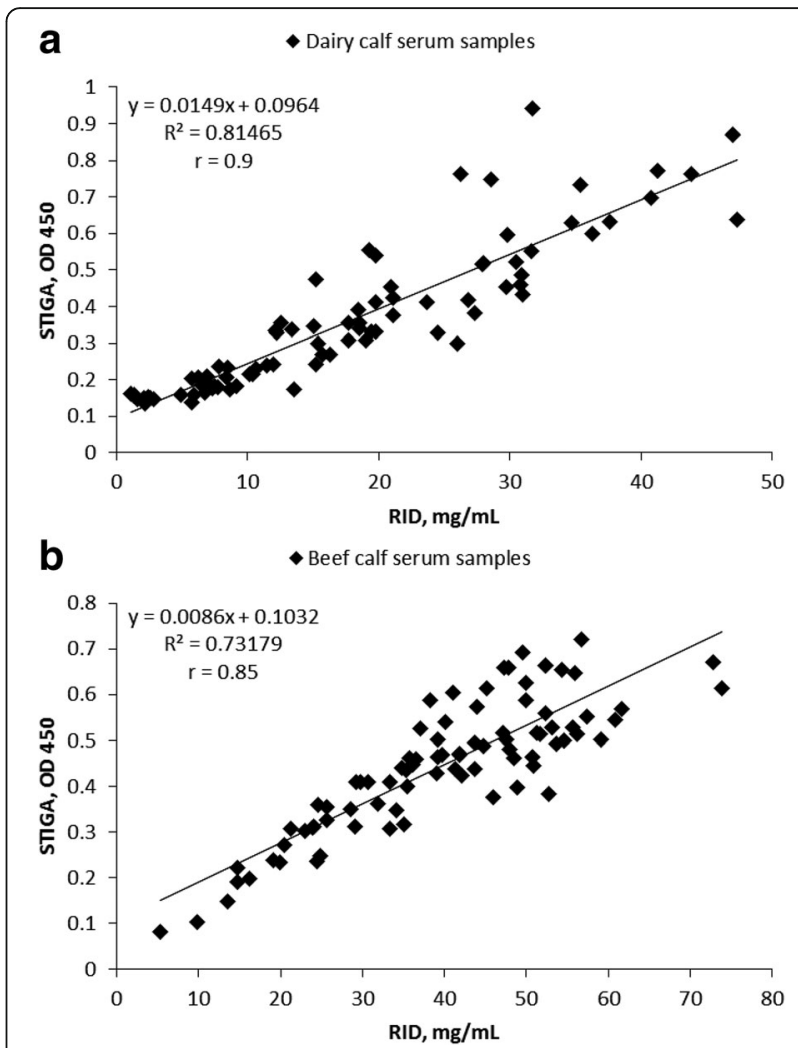

Fig. 3 Correlation between RID determined lgG concentrations in serum and glucose levels determined by STIGA. Scatter plot comparing Ig concentrations determined by RID $(\mathrm{mg} / \mathrm{mL})$ and by STIGA

(determined as optical density OD 450) in: a, dairy calf sera ( $n=83)$; b, beef calf sera $(n=84)$

\section{Detection of IgGs by STIGA using a glucometer (STIGA ${ }^{\text {FIELD) }}$}

In order to evaluate STIGA for future on farm use, a smaller sample set for each test group was analyzed with an assay variant, STIGA ${ }^{\text {FIELD }}$. The correlation coefficients between RID determined IgG concentrations and glucose levels determined by STIGA ${ }^{\text {FIELD }}$ were 0.7 for dairy colostrum, 0.85 for beef colostrum, 0.94 for dairy calf sera, and 0.83 for beef calf sera (Fig. 5).

\section{Discussion}

In this study, we described a novel assay named STIGA to measure the IgG concentration in bovine colostrum and serum. In contrast to the majority of assays developed for this purpose, STIGA is able to directly measure

Table 3 Diagnostic test characteristics for STIGA in blind study

\begin{tabular}{llllll}
\hline & Cut point, OD 450 & Accuracy, $\%$ & Se, \% & Sp, \% & PPV, \% \\
\hline Colostrum & 0.5 & 90 & 100 & 71.43 & 100 \\
Serum & 0.4 & 96 & 100 & 94.73 & 85.71 \\
\hline
\end{tabular}

Accuracy, sensitivity (Se), specificity (Sp), positive predictive value (PPV), and negative predictive value (NPV) calculated for OD cut point for detecting adequate quality colostrum with STIGA with cut-offs of $50 \mathrm{mg} / \mathrm{mL} \mathrm{lgG}$ for dairy colostrum and for detecting FTPI with STIGA with cut-offs of $10 \mathrm{mg} / \mathrm{mL}$ lgG for dairy calf sera determined by RID; for dairy colostrum $(n=25)$ and dairy calf sera $(n=20)$ 


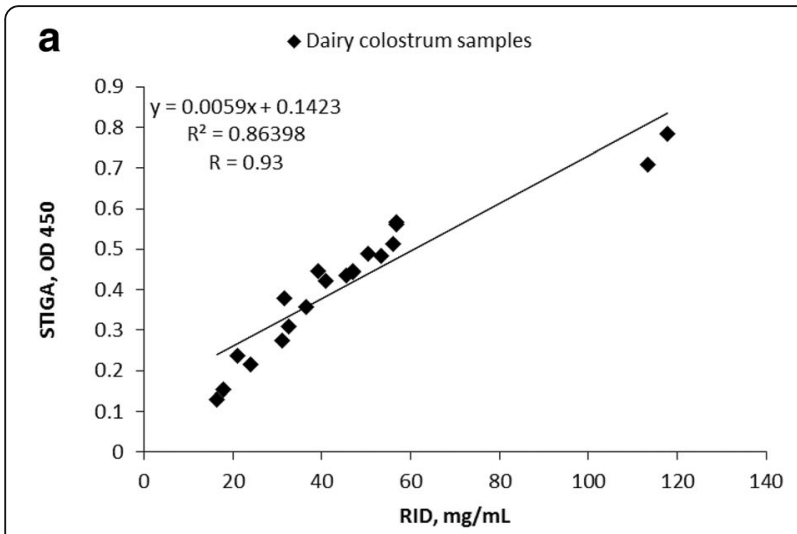

b
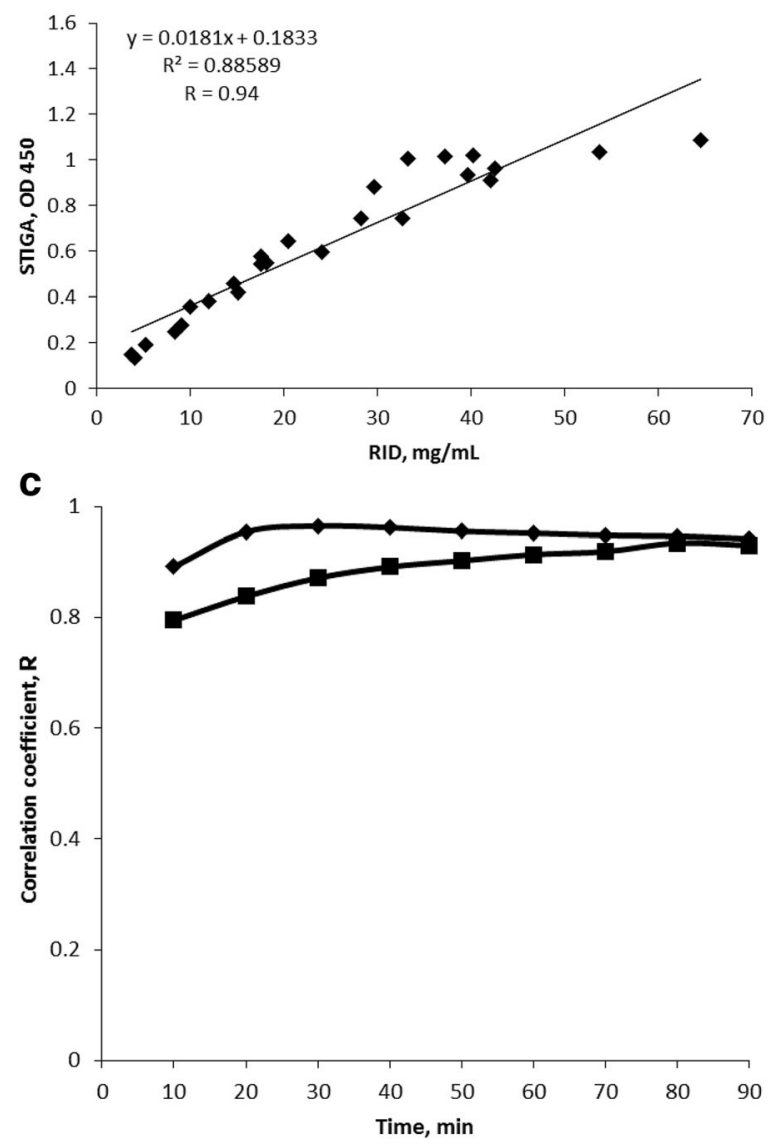

Fig. 4 Correlation between RID determined IgG concentrations in colostrum and serum and glucose levels determined by STIGA in blind study. Scatter plot comparing lgG concentrations determined by RID ( $\mathrm{mg} / \mathrm{mL}$ ) and by STIGA (determined as optical density OD $450)$ in blinded study: $\mathbf{a}$, dairy colostrum $(n=20)$; $\mathbf{b}$, dairy calf sera $(n=25)$; c, correlation coefficient between RID $(\mathrm{mg} / \mathrm{mL})$ and STIGA (OD 450) during the assay (squares - colostrum samples; diamonds - serum samples)

IgGs mediated by specific interaction of the STIGA reagents with IgGs.

Currently, there are several methods used to estimate IgG content in bovine colostrum and calf serum. Radial immunodiffusion estimates IgG concentration directly and, currently, is considered the gold standard for both colostrum and calf serum [11]. However, RID is a lab-based test that requires expensive reagents and long processing times, making it unsuitable for on-farm use. The colostrometer and Brix refractometer (optical or digital) are two devices most commonly used on farms to access colostrum quality [15-19]. Colostrometers measure the specific density of colostrum whereas the Brix refractometer measures its refraction index. Both of these methods have the disadvantage of estimating IgG concentration indirectly by measuring colostrum properties that are proxies for IgG concentration. These methods can lead to the overestimation of IgG concentration $[7,9]$. Apart from these, there have been a number of other techniques explored including infrared spectroscopy (IR) [9] and immunoassays (IM) [20]. Although more sensitive than other assays, IR still requires expensive equipment and analysis of the acquired data [9], whereas the disadvantage of IM is that they only provide positive or negative results without any quantification of IgG [20]. For determination of IgG in calf sera, several tests are available such as sodium sulphate and zinc sulphate turbidity tests, immunoassays, measurement of g-glutamyl transferase activity, glutaraldehyde coagulation tests, and Brix refractometry [4, 21]. Apart from the immunoassays [22], including ELISA, these tests also have the disadvantage of not measuring IgG directly. Furthermore, many of them have poor sensitivity and specificity and require a lab setting and skilled personnel to perform the test.

Compared with the two most frequently used methods to analyse dairy colostrum, colostrometer and Brix, STIGA had the same level of agreement with RID, comparable sensitivity and improved specificity [7]. Applied to serum, STIGA has a high correlation with RID, as well as high sensitivity and specificity. Furthermore, when tested with fresh colostrum and serum samples of unknown concentrations, STIGA reached much higher level of agreement with RID then has been reported for Colostrometer or Brix assay [7]. Its sensitivity, specificity, PPV and NPV were improved as well. Furthermore, inter and intra assay variability were within the generally expected range [23]. The correlation value was high after the first $10 \mathrm{~min}$, indicating that assay time could be much shorter than used in this study.

Moreover, direct measurement of the IgG offered by STIGA and RID overcomes many limitations and inaccuracies that arise from indirect determination of IgG. For example, colostrometer measurements are temperature dependent. Hence, if samples are not at room temperature $\left(22{ }^{\circ} \mathrm{C}\right)$ when analysed, their IgG content will not be correctly determined. The measurements obtained by the Brix method, although more reliable than the colostrometer, 


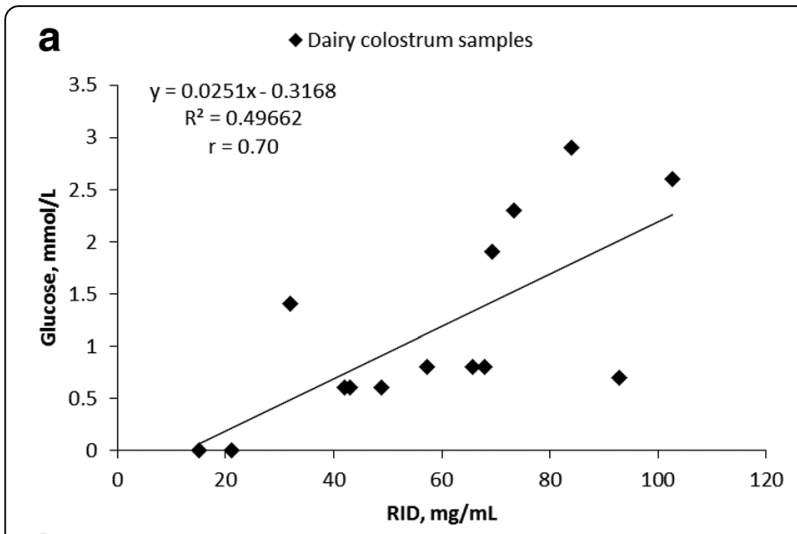

b

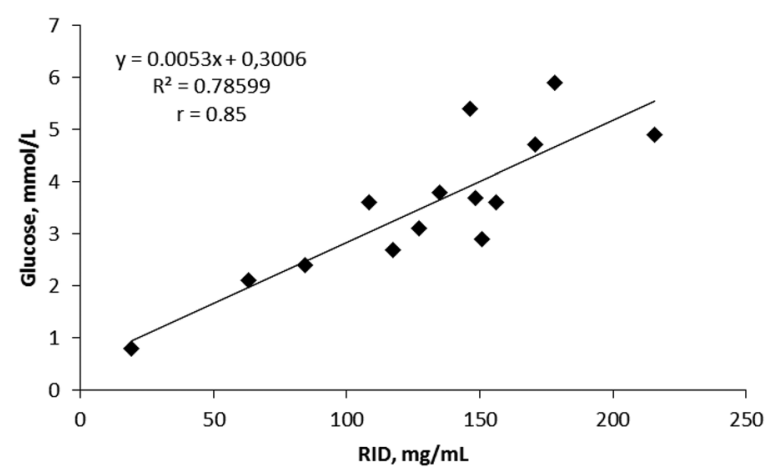

C Dairy calf serum samples

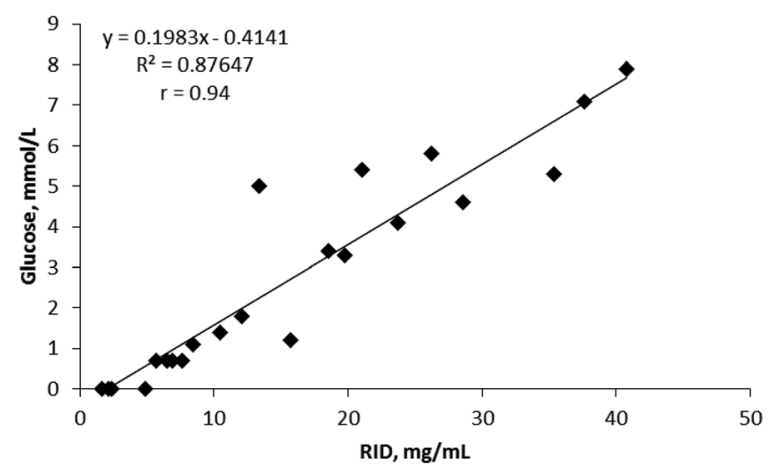

d Beef calf serum samples

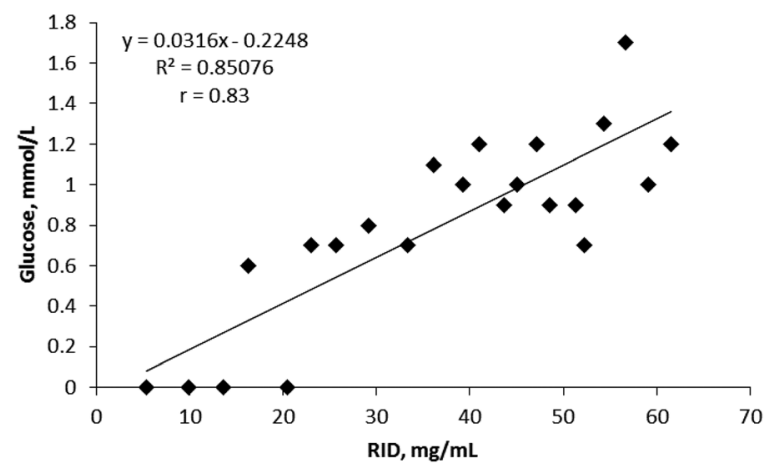

Fig. 5 Correlation between RID determined IgG concentrations in colostrum and serum and glucose levels determined by STIGA FIELD Scatter plots of IgG concentration measured by STIGA ${ }^{\text {FIELD }}$ (mmol/L of glucose measured by glucometer) and concentration determined by RID $(\mathrm{mg} / \mathrm{mL})$ for: $\mathbf{a}$, dairy colostrum samples $(n=14)$; $\mathbf{b}$, beef colostrum samples $(n=14)$; , dairy calf serum samples $(n=22)$; d) beef calf serum samples $(n=22)$

measures total solid content to estimate IgG content and can be influenced by factors like nutrition that change the total solid but not the IgG concentration [24, 25]. Similarly, hydration status of the calves and type of colostrum used for first feed influence the total protein in calf serum. The Immunoassay kit (Colostrum bovine IgG quick test kit, Midlands Bio-Products, Boone, Iowa, USA) [20, 22] is the only on-farm method that directly measures IgG in colostrum or serum, but this test has the major disadvantage of not providing information about the actual concentration of the IgG in the sample but rather a YES or NO answer if the cut-off point was reached or not. While reaching the cut-off point might be sufficient to establish if FTPI occurred, this assumes the cut-point used by the assay is accurate and sufficient for all calves on all farms. Similarly, it is useful to know the exact IgG concentration when measuring the colostrum quality to ensure the actual volume of colostrum being fed to calves is sufficient to avoid FTPI.

STIGA has some advantages compared with RID. STIGA is faster, requiring only $90 \mathrm{~min}$ or less as opposed to $24-48 \mathrm{~h}$ required for RID [11], is less laborious, and is suitable for automatization. Furthermore, since all STIGA reagents are produced by a recombinant expression system (E. coli), STIGA eliminates the need to use animals for production of reagents (polyclonal antisera), which are necessary for RID [11]. This makes STIGA less expensive than RID and more reliable since the variation between different batches of polyclonal antisera produced can be reduced to a minimum.

Glucose is naturally present in both bovine colostrum and in serum. In colostrum, free glucose can be found only in traces and around $2.9 \%$ as a part of lactose [26]. In serum of newborn calves, glucose levels can be as high as $7 \mathrm{mmol} / \mathrm{L}$ [27]. Still samples are diluted prior to STIGA detection and this step brings free glucose concentration under the detection threshold while the glucose as part of lactose or other compounds cannot be detected by this assay due to the substrate specificity of trehalase.

A limitation of this study was the use of opportunistic samples. The quality of samples (e.g. storage of the samples or freeze and thaw cycles) could have impacted the performance of the test as has been shown in other studies [28]. This concern was addressed in the blinded study where STIGA was tested on fresh samples and showed much better performance, indicating that STIGA 
could be more efficient than the other assays in diagnosing poor quality colostrum or FTPI.

Although STIGA was performed in a laboratory setting for this study, the performance of STIGA was examined in a user-friendly format that could be optimized for field-testing $\left(\mathrm{STIGA}^{\text {FIELD}}\right)$. Strong correlations with

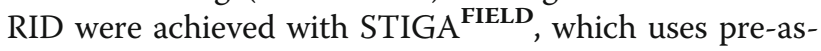
sembled freeze-dried reagents and a commercially available handheld glucometer for detection of the output signal. This format does not require any assembly of test, but rather only application of the diluted sample; hence, it eliminates the need for laboratory equipment and specifically trained personnel.

\section{Conclusions}

We demonstrated that STIGA is as efficient in detecting IgG levels as other devices on the market while having the advantage of being a single step protocol applicable to different sample types (colostrum and serum). The unique feature of this test to directly detect IgG and to produce an easily measurable output signal that makes this test a promising precursor for future field testing.

\section{Abbreviations}

FTPI: Failure of transfer of passive immunity; IgG: Immunoglobulins G; IM: Immunoassays; IR: Infrared spectroscopy; NPD: Negative predictive value; OD: Optical density; PPD: Positive predictive value; RID: Radial immunodiffusion; STIGA: Split Trehalase IgG quantification assay

\section{Acknowledgments}

We would like to acknowledge Amanda Bartier who collected the dairy colostrum and serum samples and Elizabeth Homerosky and Jennifer Pearson who collected the beef colostrum and serum samples. We are also grateful for the work done by Director of Quality Assurance, Ron Sargent, and other SCCL managers and staff in selecting and testing the colostrum and sera for the blinded study.

\section{Funding}

Natural Sciences and Engineering Research Council of Canada, Discovery Grant to JDB.

\section{Availability of data and materials}

Please contact author for data requests.

\section{Authors' contributions}

Conceived and designed the experiments: MD, JDB. Prepared and performed the experiments: MD, SO, YF. Analyzed the data: MD, CW, JDB. Contributed reagents/materials/analysis tools: CW, LD, JDB. Wrote the paper: MD, CW, LD, JDB. All authors read and approved the final manuscript.

\section{Ethics approval}

No samples from animals were collected specifically for this study. Only samples from existing collections were used.

\section{Consent for publication}

Not applicable.

\section{Competing interests}

JDB has a patent application pending on the STIGA technology.
Received: 30 April 2018 Accepted: 22 August 2018

Published online: 27 August 2018

\section{References}

1. McGuirk SM, Collins M. Managing the production, storage, and delivery of colostrum. Vet Clin North Am Food Anim Pract. 2004;20:593-603.

2. Godden S. Colostrum management for dairy calves. Vet Clin North Am Food Anim Pract. 2008;24:19-39.

3. Beam AL, Lombard JE, Kopral CA, Garber LP, Winter AL, Hicks JA, et al. Prevalence of failure of passive transfer of immunity in newborn heifer calves and associated management practices on US dairy operations. J Dairy Sci. 2009;92:3973-80.

4. Weaver DM, Tyler JW, VanMetre DC, Hostetler DE, Barrington GM. Passive transfer of colostral immunoglobulins in calves. J Vet Intern Med. 2000;14: 569-77.

5. Dewell RD, Hungerford LL, Keen JE, Laegreid WW, Griffin DD, Rupp GP, et al. Association of neonatal serum immunoglobulin G1 concentration with health and performance in beef calves. J Am Vet Med Assoc. 2006; 228:914-21.

6. Waldner $\mathrm{CL}$, Rosengren $\mathrm{LB}$. Factors associated with serum immunoglobulin levels in beef calves from Alberta and Saskatchewan and association between passive transfer and health outcomes. Can Vet J. 2009;50:275-81.

7. Bartier AL, Windeyer MC, Doepel L. Evaluation of on-farm tools for colostrum quality measurement. J Dairy Sci. 2015;98:1878-84.

8. Trotz-Williams LA, Leslie KE, Peregrine AS. Passive immunity in Ontario dairy calves and investigation of its association with calf management practices. J Dairy Sci. 2008;91:3840-9.

9. Elsohaby I, McClure JT, Cameron M, Heider LC, Keefe GP. Rapid assessment of bovine colostrum quality: how reliable are transmission infrared spectroscopy and digital and optical refractometers? J Dairy Sci. 2017;100: $1427-35$.

10. McBeath DG, Penhale WJ, Logan EF. An examination of the influence of husbandry on the plasma immunoglobulin level of the newborn calf, using a rapid refractometer test for assessing immunoglobulin content. Vet Rec. 1971:88:266-70

11. Chelack BJ, Morley PS, Haines DM. Evaluation of methods for dehydration of bovine colostrum for total replacement of normal colostrum in calves. Can Vet J. 1993;34:407-12.

12. Drikic M, De Buck J. Split trehalase as a versatile reporter for a wide range of biological analytes. In: Biotechnol Bioeng; 2018;115(5):1128-36.

13. Gibson RP, Gloster TM, Roberts S, Warren RA, Storch de Gracia I, Garcia A, et al. Molecular basis for trehalase inhibition revealed by the structure of trehalase in complex with potent inhibitors. Angew Chem Int Ed Engl. 2007; 46:4115-9.

14. Wilton DJ, Tunnicliffe RB, Kamatari YO, Akasaka K, Williamson MP. Pressureinduced changes in the solution structure of the GB1 domain of protein G. Proteins. 2008; $71: 1432-40$.

15. Fleenor WA, Stott GH. Hydrometer test for estimation of immunoglobulin concentration in bovine colostrum. J Dairy Sci. 1980;63:973-7.

16. Chigerwe M, Tyler JW, Middleton JR, Spain JN, Dill JS, Steevens BJ. Comparison of four methods to assess colostral IgG concentration in dairy cows. J Am Vet Med Assoc. 2008;233:761-6.

17. Bielmann V, Gillan J, Perkins NR, Skidmore AL, Godden S, Leslie KE. An evaluation of brix refractometry instruments for measurement of colostrum quality in dairy cattle. J Dairy Sci. 2010;93:3713-21.

18. Morrill KM, Conrad E, Polo J, Lago A, Campbell J, Quigley J, et al. Estimate of colostral immunoglobulin $\mathrm{G}$ concentration using refractometry without or with caprylic acid fractionation. J Dairy Sci. 2012;95:3987-96.

19. Quigley JD, Lago A, Chapman C, Erickson P, Polo J. Evaluation of the brix refractometer to estimate immunoglobulin $\mathrm{G}$ concentration in bovine colostrum. J Dairy Sci. 2013;96:1148-55.

20. Chigerwe M, Dawes ME, Tyler JW, Middleton JR, Moore MP, Nagy DM. Evaluation of a cow-side immunoassay kit for assessing lgG concentration in colostrum. J Am Vet Med Assoc. 2005;227:129-31.

21. Tyler JW, Hancock DD, Parish SM, Rea DE, Besser TE, Sanders SG, et al. Evaluation of 3 assays for failure of passive transfer in calves. J Vet Intern Med. 1996;10:304-7.

22. Dawes ME, Tyler JW, Hostetler D, Lakritz J, Tessman R. Evaluation of a commercially available immunoassay for assessing adequacy of passive transfer in calves. J Am Vet Med Assoc. 2002;220:791-3. 
23. Andreasson U, Perret-Liaudet A, Van Waalwijk van Doorn L, Blennow K, Chiasserini D, Engelborghs $S$, et al. A practical guide to immunoassay method validation. Front Neurol. 2015;6:179.

24. Rastani RR, Grummer RR, Bertics SJ, Gumen A, Wiltbank MC, Mashek DG et al. Reducing dry period length to simplify feeding transition cows: milk production, energy balance, and metabolic profiles. J Dairy Sci. 2005;88: 1004-14.

25. Morin DE, Constable PD, Maunsell FP, McCoy GC. Factors associated with colostral specific gravity in dairy cows. J Dairy Sci. 2001;84:937-43.

26. Morrill KM, Conrad E, Lago A, Campbell J, Quigley J, Tyler H. Nationwide evaluation of quality and composition of colostrum on dairy farms in the United States. J Dairy Sci. 2012;95:3997-4005.

27. Knowles TG, Edwards JE, Bazeley KJ, Brown SN, Butterworth A, Warriss PD. Changes in the blood biochemical and haematological profile of neonatal calves with age. Vet Rec. 2000;147:593-8.

28. Morrill KM, Robertson KE, Spring MM, Robinson AL, Tyler HD. Validating a refractometer to evaluate immunoglobulin $\mathrm{G}$ concentration in Jersey colostrum and the effect of multiple freeze-thaw cycles on evaluating colostrum quality. J Dairy Sci. 2015;98:595-601.

Ready to submit your research? Choose BMC and benefit from:

- fast, convenient online submission

- thorough peer review by experienced researchers in your field

- rapid publication on acceptance

- support for research data, including large and complex data types

- gold Open Access which fosters wider collaboration and increased citations

- maximum visibility for your research: over $100 \mathrm{M}$ website views per year

At $\mathrm{BMC}$, research is always in progress.

Learn more biomedcentral.com/submissions 